\title{
Overall study on molecular pathways of skin cancer derived from Ultra- violet radiation as an environmental threat
}

\author{
Hossein Yousefi ${ }^{1}$ Samira Mmohammadzadeh $^{2}{\text { Arsalan } \text { Irompour }^{3} \text {, Neda Shenasifam }}^{4}$ \\ Elham roshandel $^{5}$, Arsalan Jalili ${ }^{4}$
}

Received:20.08.2015

Revised:25.09.2015

Accepted: 30.10.2015

\begin{abstract}
An important part of solar radiation is considered to be Ultraviolet radiation. Though through passing ozone layer it is progressively filtered. Due to the depletion of the ozone layer, the filtering activity of the latter is reduced and as a result more UV radiation, UVB in particular, reaches the Earth's surface. Ultraviolet radiation is composed of three different wavelengths: UVA, UVB and UVC. Although UVC isn't a cause of skin cancer, UVA and UVB play different roles as for tanning, burning, and photo aging. As a matter of fact, Ultraviolet light can damage DNA in the epidermis. However, through apoptosis the damaged DNA is repaired or deleted in order to prevent the generation of cancer. It is believed that a deficient apoptotic mechanism might make individuals liable to skin cancer. The main factor for generating skin cancer is considered to be the UV radiation which could cause basal cell carcinoma, squamous cell carcinoma and possibly melanoma. For the maintenance of hemostasis, apoptosis plays a key role. This is done via many molecular pathways such as the pathways of tumor suppressor genes like P53, P21 and also the expression of BAX proteins. These pathways are involved in apoptosis after UV radiation. It is clear that the malfunction of these genes and proteins can lower the tolerance of body and cause cancer. The goal of this article is to investigate the molecular pathways of skin cancer derived from Ultra violet radiation as an environmental threat.
\end{abstract}

\section{Skin cancer}

Cancer is a group of diseases that is defined by abnormal cell growth which can ultimately spread or invade other parts of the body (1-3). A variety of factors could cause cancer (4-7). Skin cancers are a group of cancers that are related to skin. The three main types of skin cancer are: Melanoma (pic1), Basal-cell cancer (pic2) and Squamous-cell cancer (pic3) (810). The first two of the latter, alongside some other less common skin cancers are known as non-melanoma skin cancer. Basal-cell cancer grows with a rather slow rate and can damage the tissue around it. Though it is unlikely to spread Squamous-cell cancer has a good potential to spread. It usually appears as a hard lump with a scaly top though it may also form an ulcer (14, 15). Melanomas are the most aggressive type. Signs include a mole that has changed in size,

\section{Author's Address}

Faculty of New Sciences and Technologies, University of Tehran, Tehran, Iran

Department of Hematology, Faculty of Medical Sciences, Shahid Behehshti University, Tehran, Iran.

Bachelor of clinical laboratory sciences, Islamic Azad University of Chaloos, Chaloos, Iran.

Department of Biology School of Basic Science, East Tehran Branch of Islamic Azad University, Tehran, Iran Department of Hematology, faculty of Medical Science, Tabrbiat Modares University

Email: jalili.arsalan@yahoo.com shape and color. It possesses irregular edges and usually has more than one color. Moreover, it is itchy or bleeds (16-19).

\section{Ultraviolet radiation and DNA damage}

Ultraviolet light results in DNA damage. If left unrepaired, it can give rise to several biological effects such as cell death, mutation and cancer $(22,23)$. Xeroderma Pigmentosum, A human related disease, is a remarkable example of how reduced DNA repair capacity can lead to a higher rate of cell lethality, higher mutation frequency and a predisposition to cancer (24-26). By nucleotide excision repair process, which is a complex interaction of more than 10 different types of gene products, the repair of UV-induced DNA damage is achieved. $(27,28)$. As shown by an increasing number of evidence DNA repair, like any phenotypic trait, would be heterogeneously distributed in the human population (29). As a result, specific individuals who possess low DNA repair capacity might be more susceptible to the adverse biological effects of environmental genotoxic agents, for example UV light $(30,31)$. Apoptosis is a process which deals with the repair of damaged DNA in order to prevent the generation of cancer. (32). A deficient apoptotic mechanism is believed to make individuals susceptible to skin cancer. Thus, the reaction and response of normal 
controls and patients with basal cell carcinoma to distant areas or cause death. It usually appears as a painless raised area of skin which in some occasions might be shiny and contain small
(BCC) to UV irradiation was investigated 33,34). blood vessels running over it or may show itself as a raised area with an ulcer (11-13).

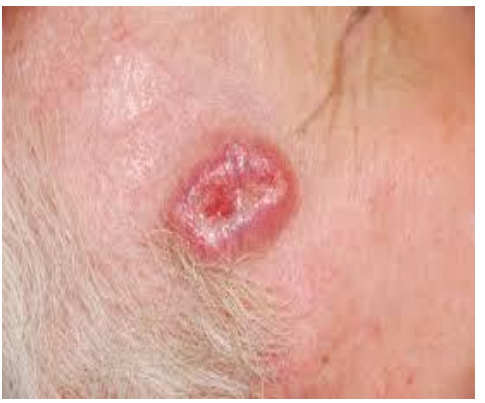

Fig. 1: Melanoma

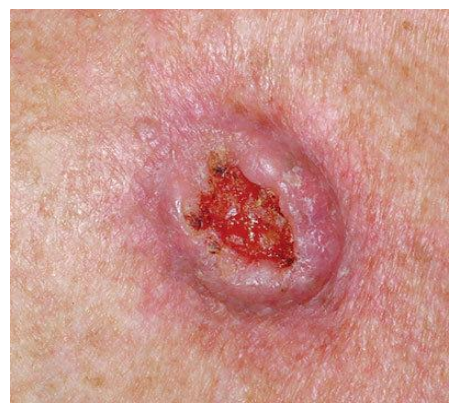

Fig.2: Basal cell carcinoma carcinoma

\section{Ultra violet radiation and its effect on skin cancer:}

Solar radiation has many components, for example UV. Through passing the ozone layer, UV is progressively filtered. As a result of ozone layer depletion, such protective activity is reduced and therefore, more UV radiation will reach to the Earth's surface. $(35,36)$. UV radiation has three wavelengths: UVA, UVB and UVC (37). Although UVC isn't an initiative of skin cancer, UVA and UVB play different roles as for tanning, burning, and photoaging (38). Because there is no fully proven answer about the best way to get vitamin $\mathrm{D}$, and also the controversy about tanning beds, we still face a great deal of misinformation regarding UV radiation. (39).

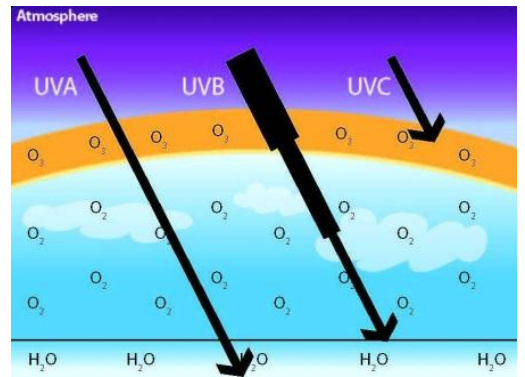

\section{Picture4: Penetration of UVA, UVB and UVC into different layers of atmosphere (40).}

Though the fact that UV radiation is the main responsible factor for skin cancers, including basal cell carcinoma, squamous cell carcinoma and possibly melanoma remains true $(41,42)$. This is further proven by the National Institutes of Health and the World Health Organization since they have categorized broad spectrum UV as a human carcinogen $(43,44)$. The solar UV spectrum is continuous, yet it would be scientifically convenience to describe the light within three specific wavebands; UVA, UVB and UVC based on their wavelength. They are different due their biological impact and the depth of which they can penetrate skin. (45-48). UVA has a wavelength of $320-400 \mathrm{~nm}$ and is responsible for up to 95 percent of the solar UV radiation that reaches the Earth's surface. Due to its strong penetration through skin, for many years it has been hold responsible, as a major factor, for skin aging and wrinkling. In addition, recent studies' findings suggest that UV radiation might initiate and exacerbate the development of skin cancers (49-50). UVA radiation is present during all daylight hours and alongside winter months. Also, it can pass through glass and clouds. Therefore the exposure of humans to UV radiation in their lifetime is great. $(51,52)$. Recent findings propose that UVA exposure could deal the same amount of damage to skin as UVB. Until recently scientists believed that although UVA penetrates more deeply through the skin compared to UVB, it would be absorbed less by DNA and therefore, would do a lower damage when compared to UVB. (53, 54). However based on a recent Australian-US study, UVA is more harmful than UVB to the genetic material of skin cell where most skin cancers arise which is the keratinocytes in the basal layer of the epidermis $(55,56)$. Superficial epidermal layers are more susceptible to UVB radiation (picture5). Being responsible for burning, tanning, acceleration of skin aging, UVB has a wavelength of 290-320 nm. In addition, it plays a key role in the development of skin cancer. (57, 
58). The intensity of UVB depends on many factors like season, location and time of day. UVC has the shortest wavelength of the three (less than $290 \mathrm{~nm}$ ) and as a result, it possesses the highest amount of energy. It should be stated however, since UVC is filtered and is not able to pass through the ozone layer, these wavelengths do not reach the Earth's surface and aren't able to do harm to human skin. The differences between the effects of UBV and UVA are yet to be fully uncovered. But when these two are combined, they are to pose a serious threat to the skin (59). It can create irreversible damage that varies from sunburn to premature aging and ultimately to skin cancer. In order to avoid such harm, protection from these rays seems to be the only solution.

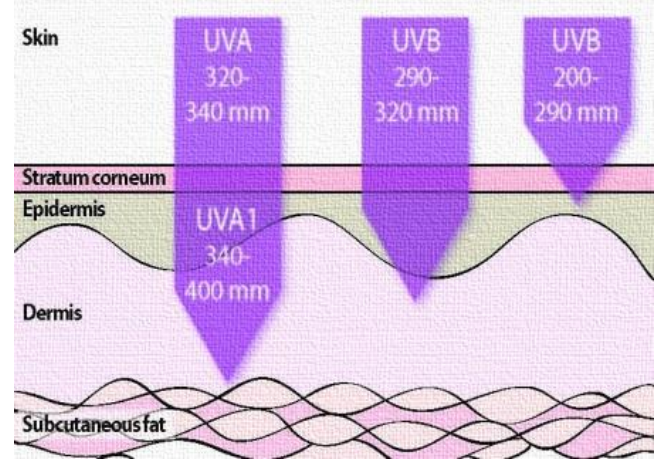

Picture5: Penetration of UVA, UVB and UVC into different layers of superficial epidermal layers (40).

4.Efficiency of biomarkers in detection of cell damage

Biomarkers are cellular, biochemical, or molecular alterations. Such molecules are measurable in biological media such as human tissues' cells or fluids $(60,61)$. Some carcinogens affect living cells by altering genes while some others are able to cause reactive chemical compounds that result in oxidative stress. $(62,63)$. UV radiation affects a range of molecules in living tissues including DNA. Therefore, using biological exposure markers could give us many advantages in terms of understanding exposure estimates. In addition, it would give us the ability to validate other measures of exposure and also increase the knowledge of intermediate steps in pathways regarding the exposure to disease. UV response is a stress response as DNA damage when the mammalian cells are exposed to Ultraviolet radiation. Several transcription factors are involved in such induction, including AP-1, NF-kB and p53 (64-66).It seems that only p53 is directly induced in response to UVdamaged DNA. On the other hand, AP-1 and NF-kB are activated through signal transduction cascades which appear to be elicited by effects of short wavelength UV on the cell surface, separately from DNA damage $(67,68)$. Specific signal-responsive protein kinases are of utmost important in such pathways. It should be mentioned that the protein kinase involved in NF-kB activation is not molecularly identified. The activation of AP-1 and NF-kB have both been suggested to play roles in diverse and conflicting responses including apoptosis, tumor promotion, protection against radiation induced damage and finally, aging (69-71). Since UV light is a common carcinogen and genotoxic agent to which patients are exposed, understanding the function of UV activated protein kinases seems to be of utmost importance for both physiological and clinical purposes.

\section{P53 and P21 genes functions against UV exposure:}

P53 and P21 genes are tumor genes which function against the occurrence of cancer (72,73). After and UV radiation, P53 gene prevents cancer formation and maintains the cellular genetic stability (74). The amount of p53 protein is increased after UV radiation. This response is believed to induce cell cycle arrest, support nucleotide excision repair (NER) and apoptosis $(75,76)$. Also, the NER increases when low doses of radiation are involved. In contrast, apoptosis takes place only after high doses of radiation are received by cells (over 200 $\mathrm{J} / \mathrm{m} 2$ ). P21 is a tumor suppression gene which is tightly controlled by 553 gene. This protein mediates the p53-dependent cell cycle $\mathrm{G}_{1}$ phase arrest as a response to a variety of stress inducers (picture 6) (77-79). This was a major discovery in the early 1990s since it revealed how cells stop dividing after the exposure to harmful agents such as radiation. P21waf1/cip1 is induced by low dosages solely. Bax though, is induced only after high doses of UV radiation and thus, supporting the roles of $\mathrm{p} 21 \mathrm{waf} 1 / \mathrm{cip} 1$ and bax in NER and apoptosis, respectively $(80,81)$.These results show that UV dose, DNA repair after low doses and apoptosis after high doses are the main factors that determine cellular stress response to UV radiation. Both of the aforementioned mechanisms are dependent on wild-type p53 function. 


\section{DNARepair}

\section{Phosphorylation Acetylation Methylation}

\section{$\mathrm{G}_{2}$ Arrest}

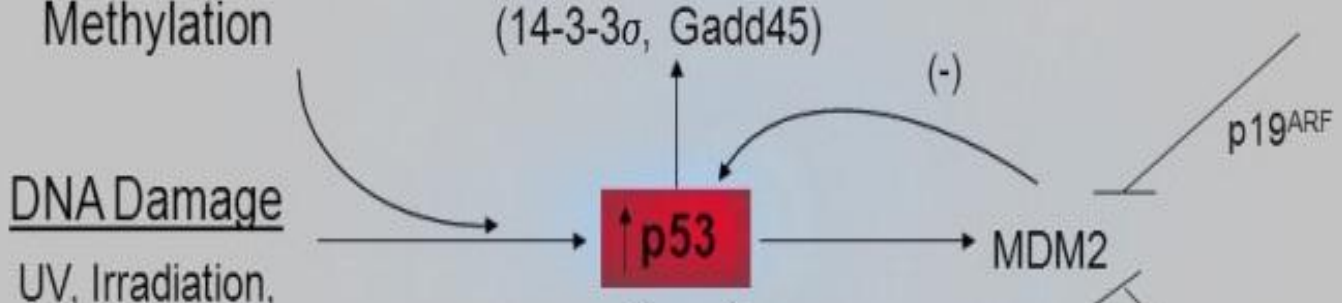

UV, Irradiation, Genotoxic Compounds

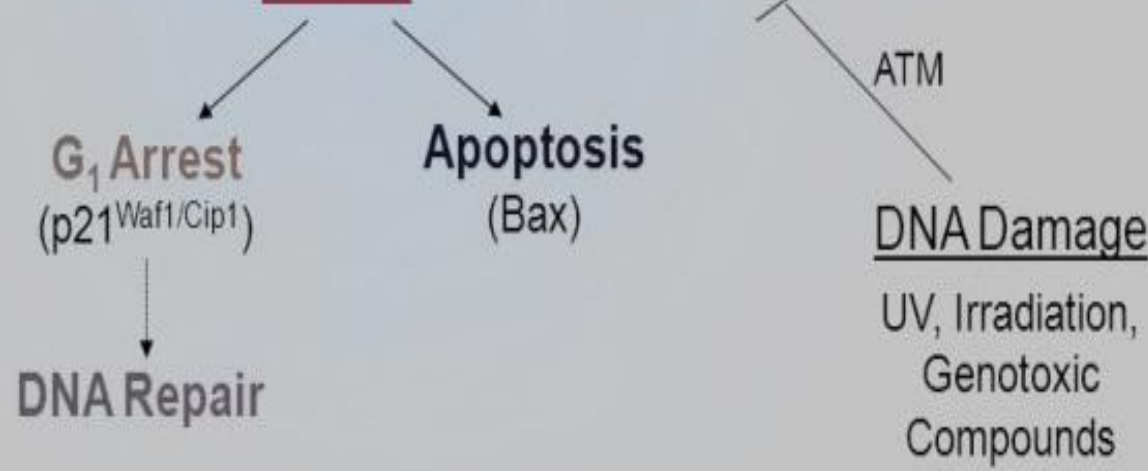

\section{Picture number 6: P53 gene and its subsequent pathways after DNA damage by UV} radiation

\section{Conclusion:}

Ozone layer depletion has resulted in many harmful events. One of which is skin cancer. UV exposure in specific parts of the planet with lower protection levels due to the ozone layer depletion has resulted in different types of skin cancer. Studying the molecular pathways that are related to the occurrence and progress of different kinds of cancers is without debt, a crucial matter and needs urgent and in depth further studies, for both research and clinical purposes.

\section{References:}

[1] Arsalan Jalili, Elham Roshandel, SeyyedHossein Fattahi, Neda Shenasifam, Amin Ebrahim Sadrabadi,Mahshid Akhavan Rahnama, SayehParkhideh. "Appraising the increased expression ofp21and p53 genes in paraffinembedded biopsy tissues of patients with bladder cancer exposed to mitomycin C" Advances inBioresearch. 10, no.3 (2016).

[2] Arsalan Jalili, Amin Ebrahimi Sadrabadi, and Asahar sShakeri yekta. "assessing the expression of braf gene in paraffin-embedded blocks of patients with colorectal cancer." (2015).

[3] Amin Ebrahimi sadrabadi, Sahar shakeri yekta, Seyyed Hossein Fattahi,Sedigheh Molaei, Somayeh Piri Gavgani, Elham Roshandel, Arsalan Jalili, "Assessing the decreased expression of TP53, P21 and in colorectal cancer" Indian Journal of Fundamental and Applied Life Sciences. 5, no.54 (2015).

[4] Marks, Paul A., Richard A. Rifkind, Victoria M. Richon, Ronald Breslow, Thomas Miller, and William K. Kelly. "Histone deacetylases and cancer: causes and therapies." Nature Reviews Cancer 1, no. 3 (2001): 194-202.

[5] Wagner, L. I., and D. Cella. "Fatigue and cancer: causes, prevalence and treatment approaches." British Journal of Cancer 91, no. 5 (2004): 822-828. 
[6] Diepgen, T. L., and V. Mahler. "The epidemiology of skin cancer." British Journal of Dermatology 146, no. s61 (2002): 1-6.

[7] Ziegler, Annemarie, Alan S. Jonason, David J. Leffellt, Jeffrey A. Simon, Harsh W. Sharma, Jonathan Kimmelman, Lee Remington, Tyler Jacks, and Douglas E. Brash. "Sunburn and p53 in the onset of skin cancer." Nature372, no. 6508 (1994): 773-776.

[8] Gallagher, Richard P., Becky Ma, David I. McLean, C. Paul Yang, Vincent Ho, J. Alastair Carruthers, and Laurence M. Warshawski. "Trends in basal cell carcinoma, squamous cell carcinoma, and melanoma of the skin from 1973 through 1987." Journal of the American Academy of Dermatology 23, no. 3 (1990): 413-421.

[9] Karagas, Margaret R., Thérèse A. Stukel, E. Robert Greenberg, John A. Baron, Leila A. Mott, and Robert S. Stern. "Risk of subsequent basal cell carcinoma and squamous cell carcinoma of the skin among patients with prior skin cancer." Jama 267, no. 24 (1992): 3305-3310.

[10] Koh, D., H. Wang, J. Lee, K. S. Chia, H. P. Lee, and C. L. Goh. "Basal cell carcinoma, squamous cell carcinoma and melanoma of the skin: analysis of the Singapore Cancer Registry data 1968-97." British journal of Dermatology148, no. 6 (2003): 1161-1166.

[11] Tool, Drug Interaction. "Basal cell carcinoma."

[12] Navya, P. V., and P. K. Shiny. "A NEW TOPOLOGY FOR THE DETECTION AND CLASSIFICATION OF MELANOMA."

[13] Randle, Henry W. "Basal Cell Carcinoma Identification and Treatment of the High-Risk Patient." Dermatologic surgery 22, no. 3 (1996): 255-261.

[14] Marks, Robin. "Squamous cell carcinoma." The Lancet 347, no. 9003 (1996): 735-738.

[15] Stoll Jr, H. L. "Squamous cell carcinoma." Gene Therapy of Cancer 451 (2012): 51.

[16] Stern, Robert S., and Rudee Lange. "Nonmelanoma skin cancer occurring in patients treated with PUVA five to ten years after first treatment." Journal of investigative dermatology 91, no. 2 (1988): 120-124.

[17] Scotto, Joseph, Alfred W. Kopf, and Frederick Urbach. "Non-melanoma skin cancer among caucasians in four areas of the United States." Cancer 34, no. 4 (1974): 1333-1338.

[18] Freedman, D. M., M. Dosemeci, and K. McGlynn. "Sunlight and mortality from breast, ovarian, colon, prostate, and non-melanoma skin cancer: a composite death certificate based case-control study." Occupational and Environmental Medicine 59, no. 4 (2002): 257262.

[19] http://wrightstatephysicians.org/2013

[20]

www.onlinedermclinic.com

[21] http://doctorv.ca/

[22] Friedberg, Errol C. "DNA damage and repair." Nature 421, no. 6921 (2003): 436-440.

[23] Witkin, Evelyn M. "Ultraviolet mutagenesis and inducible DNA repair in Escherichia coli." Bacteriological reviews 40, no. 4 (1976): 869.

[24] Cleaver, J. E. "Xeroderma pigmentosum: a human disease in which an initial stage of DNA repair is defective." Proceedings of the National Academy of Sciences 63, no. 2 (1969): 428-435.

[25] Robbins, Jay H., Kenneth H. Kraemer, Marvin A. Lutzner, Barry W. Festoff, and hayden g. Coon. "Xeroderma pigmentosum: an inherited disease with sun sensitivity, multiple cutaneous neoplasms, and abnormal DNA repair." Annals of Internal Medicine 80, no. 2 (1974): 221-248.

[26] Cleaver, J. E. "Xeroderma pigmentosum: variants with normal DNA repair and normal sensitivity to ultraviolet light." Journal of Investigative Dermatology 58, no. 3 (1972): 124-128.

[27] Aboussekhra, Abdelilah, Maureen Biggerstaff, Mahmud KK Shivji, Juhani A. Vilpo, Vincent Moncollin, Vladimir N. Podust, Miroslava Protić, Ulrich Hübscher, Jean-Marc Egly, and Richard D. Wood. "Mammalian DNA nucleotide excision repair reconstituted with purified protein components."Cell 80, no. 6 (1995): 859-868. 
Wood, Richard D. "DNA damage recognition during nucleotide excision repair in mammalian cells." Biochimie 81, no. 1 (1999): 39-44.

[28] Almendro, Vanessa, Andriy Marusyk, and Kornelia Polyak. "Cellular heterogeneity and molecular evolution in cancer." Annual Review of Pathology: Mechanisms of Disease 8 (2013): 277-302.

[29] Hsu, T. C., Dennis A. Johnston, Lorraine M. Cherry, Dindyal Ramkissoon, Stimson P. Schantz, John M. Jessup, Rodger J. Winn, Linda Shirley, and Cynthia Furlong. "Sensitivity to genotoxic effects of bleomycin in humans: possible relationship to environmental carcinogenesis." International Journal of Cancer 43, no. 3 (1989): 403-409.

[30] Mitchelmore, C. L., and J. K. Chipman. "DNA strand breakage in aquatic organisms and the potential value of the comet assay in environmental monitoring." Mutation Research/Fundamental and Molecular Mechanisms of Mutagenesis 399, no. 2 (1998): 135-147.

[31] Trinei, Mirella, Marco Giorgio, Angelo Cicalese, Sara Barozzi, Andrea Ventura, Enrica Migliaccio, Elisabetta Milia et al. "A p53-p66Shc signalling pathway controls intracellular redox status, levels of oxidationdamaged DNA and oxidative stress-induced apoptosis." Oncogene 21, no. 24 (2002): 38723878.

[32] Murphy, M., M. J. E. M. F. Mabruk, P. Lenane, A. Liew, P. McCann, A. Buckley, C. O. Flatharta et al. "Comparison of the expression of p53, p21, Bax and the induction of apoptosis between patients with basal cell carcinoma and normal controls in response to ultraviolet irradiation." Journal of clinical pathology 55, no. 11 (2002): 829-833.

[33] Vučić, Majda, Jasna Talan-Hranilović, Vesna Vucelić, Sanda Rožanković, and Renata Iveković. "Tumori kože periorbitalne regije i vjeđa u razdoblju 1998 do 2002." Acta Clinica Croatica 42, no. 2 (2003): 161-164.

[34] Torres, Omar, Aapo Tanskanen, Ben Veihelmann, Changwoo Ahn, Remco Braak, Pawan K. Bhartia, Pepijn Veefkind, and Pieternel Levelt. "Aerosols and surface UV products from Ozone Monitoring Instrument observations: An overview." Journal of
Geophysical Research: Atmospheres (19842012) 112, no. D24 (2007).

[35] Caldwell, Martyn M., and Stephan D. Flint. "Stratospheric ozone reduction, solar UV-B radiation and terrestrial ecosystems." Climatic change 28, no. 4 (1994): 375-394.

[36] Frödin, T., L. Molin, and M. Skogh. "Effects of single doses of UVA, UVB, and UVC on skin blood flow, water content, and barrier function measured by laser-Doppler flowmetry, optothermal infrared spectrometry, and evaporimetry." Photo-dermatology 5, no. 4 (1988): 187-195.

[37] Gange, Richard W., Anthony D. Blackett, Ezra A. Matzinger, Betsy M. Sutherland, and Irene E. Kochevar. "Comparative protection efficiency of UVA-and UVB-induced tans against erythema and formation of endonuclease-sensitive sites in DNA by UVB in human skin." Journal of investigative dermatology 85, no. 4 (1985): 362-364.

[38] van Tienen, Ella. "SunSmart messages." Australian Pharmacist 29, no. 11 (2010): 944.

[39] (Maverakis, Emanual, Yoshinori Miyamura, Michael P. Bowen, Genevieve Correa, Yoko Ono, and Heidi Goodarzi. "Light, including ultraviolet." Journal of autoimmunity 34, no. 3 (2010): J247-J257.

[40] Gallagher, Richard P., Becky Ma, David I. McLean, C. Paul Yang, Vincent Ho, J. Alastair Carruthers, and Laurence M. Warshawski. "Trends in basal cell carcinoma, squamous cell carcinoma, and melanoma of the skin from 1973 through 1987." Journal of the American Academy of Dermatology 23, no. 3 (1990): 413-421.

[41] Gallagher, Richard P., Gerry B. Hill, Chris D. Bajdik, Andrew J. Coldman, Shirley Fincham, David I. McLean, and William J. Threlfall. "Sunlight exposure, pigmentation factors, and risk of nonmelanocytic skin cancer: II. Squamous cell carcinoma." Archives of Dermatology 131, no. 2 (1995): 164-169.

[42] World Health Organization. Cancer control: knowledge into action: WHO guide for effective programmes. Vol. 2. World Health Organization, 2007. 
[43] Levine, Jody A., Michael Sorace, James Spencer, and Daniel M. Siegel. "The indoor UV tanning industry: a review of skin cancer risk, health benefit claims, and regulation." Journal of the American Academy of Dermatology53, no. 6 (2005): 1038-1044.

[44] Meinhardt, Merve, Ronald Krebs, Angelika Anders, Ulrike Heinrich, and Hagen Tronnier. "Wavelength-dependent penetration depths of ultraviolet radiation in human skin." Journal of biomedical optics 13, no. 4 (2008): 044030044030 .

[45] Everett, Mark Allen, Edward Yeargers, Robert M. Sayre, and Robert L. Olson. "Penetration of epidermis by ultraviolet rays." Photochemistry and Photobiology 5, no. 7 (1966): 533-542.

[46] Anderson, R. Rox, and John A. Parrish. "The optics of human skin." Journal of Investigative Dermatology 77, no. 1 (1981): 13-19.

[47] KRUTMANN, Jean. "The role of UVA rays in skin aging." European Journal of Dermatology 11, no. 2 (2001): 170-1.

[48] Krotkov, N. A., P. K. Bhartia, J. R. Herman, V. Fioletov, and J. Kerr. "Satellite estimation of spectral surface UV irradiance in the presence of tropospheric aerosols: 1. Cloud-free case." Journal of Geophysical Research: Atmospheres (1984-2012) 103, no. D8 (1998): 8779-8793.

[49] Noonan, Frances P., James Dudek, Glenn Merlino, and Edward C. De Fabo. "Animal models of melanoma: an HGF/SF transgenic mouse model may facilitate experimental access to UV initiating events." Pigment cell research16, no. 1 (2003): 16-25.

[50] Sikorski, Y., A. A. Said, P. Bado, R. Maynard, C. Florea, and K. A. Winick. "Optical waveguide amplifier in $\mathrm{Nd}$-doped glass written with near-IR femtosecond laser pulses." Electronics letters 36, no. 3 (2000): 226-227.

[51] Butler, Susan T., and Scott W. Fosko. "Increased prevalence of left-sided skin cancers." Journal of the American Academy of Dermatology 63, no. 6 (2010): 1006-1010.

[52] O'Donovan, Peter, Conal M. Perrett, Xiaohong Zhang, Beatriz Montaner, Yao-Zhong Xu, Catherine A. Harwood, Jane M. McGregor, Susan L. Walker, Fumio Hanaoka, and Peter Karran. "Azathioprine and UVA light generate mutagenic oxidative damage." Science 309, no. 5742 (2005): 18711874.

[53] Douki, Thierry, Anne Reynaud-Angelin, Jean Cadet, and Evelyne Sage. "Bipyrimidine photoproducts rather than oxidative lesions are the main type of DNA damage involved in the genotoxic effect of solar UVA radiation."Biochemistry 42, no. 30 (2003): 9221-9226.

[54] Agar, Nita S., Gary M. Halliday, Ross StC Barnetson, Honnavara N. Ananthaswamy, Mark Wheeler, and Alexandra M. Jones. "The basal layer in human squamous tumors harbors more UVA than UVB fingerprint mutations: a role for UVA in human skin carcinogenesis." Proceedings of the National Academy of Sciences of the United States of America 101, no. 14 (2004): 4954-4959.

[55] Young, Antony R., Christopher S. Potten, Osamu Nikaido, Peter G. Parsons, Jack Boenders, Jonathan M. Ramsden, and Caroline A. Chadwick. "Human melanocytes and keratinocytes exposed to UVB or UVA in vivo show comparable levels of thymine dimers." Journal of investigative dermatology111, no. 6 (1998): 936-940.

[56] Brash, Douglas E., Jeffrey A. Rudolph, Jeffrey A. Simon, Anthony Lin, Gregory J. McKenna, Howard P. Baden, Alan J. Halperin, and Jan Ponten. "A role for sunlight in skin cancer: UV-induced p53 mutations in squamous cell carcinoma." Proceedings of the National Academy of Sciences 88, no. 22 (1991): 1012410128.

[57] Matsui, M. S., and V. A. DeLeo. "Longwave ultraviolet radiation and promotion of skin cancer." Cancer cells (Cold Spring Harbor, NY: 1989) 3, no. 1 (1991): 8-12.

[58] Pearse, Anthony D., Stephen A. Gaskell, and Ronald Marks. "Epidermal changes in human skin following irradiation with either UVB or UVA." Journal of investigative dermatology 88, no. 1 (1987): 83-87.

[59] Schlenk, Daniel. "Necessity of defining biomarkers for use in ecological risk assessments." Marine Pollution Bulletin 39, no. 1 (1999): 48-53.

[60] Srinivas, Pothur R., Barnett S. Kramer, and Sudhir Srivastava. "Trends in biomarker 
research for cancer detection." The lancet oncology 2, no. 11 (2001): 698-704.

[61] Bos, Johannes L. "The ras gene family and human carcinogenesis." Mutation Research/Reviews in Genetic Toxicology 195, no. 3 (1988): 255-271.

[62] Apel, Klaus, and Heribert Hirt. "Reactive oxygen species: metabolism, oxidative stress, and signal transduction." Annu. Rev. Plant Biol. 55 (2004): 373-399.

[63] Jiang, Xiao-Hua, B. C. Wong, M. C. Lin, Geng-Hui Zhu, Hsiang-Fu Kung, Shi-Hu Jiang, Dan Yang, and Shiu-Kum Lam. "Functional p53 is required for triptolideinduced apoptosis and AP-1 and nuclear factor-kB activation in gastric cancer cells." Oncogene 20, no. 55 (2001): 80098018.

[64] Lippens, Saskia, Esther Hoste, Peter Vandenabeele, Patrizia Agostinis, and Wim Declercq. "Cell death in the skin." Apoptosis 14, no. 4 (2009): 549-569.

[65] Kick, Gerold, Gerald Messer, Alwin Goetz, Gerd Plewig, and Peter Kind. "Photodynamic therapy induces expression of interleukin 6 by activation of AP-1 but not NF- $\mathrm{BB}$ DNA binding." Cancer research 55, no. 11 (1995): 2373-2379.

[66] Sato, Mayumi, Chikako Nishigori, Mohamed Zghal, Takashi Yagi, and Hiraku Takebe. "Ultraviolet-specific mutations in p53 gene in skin tumors in xeroderma pigmentosum patients." Cancer research 53, no. 13 (1993): 2944-2946.

[67] Kress, Stefan, Christian Sutter, Paul T. Strickland, Hasan Mukhtar, Jürgen Schweizer, and Michael Schwarz. "Carcinogen-specific mutational pattern in the p53 gene in ultraviolet B radiation-induced squamous cell carcinomas of mouse skin." Cancer research 52, no. 22 (1992): 6400-6403.

[68] Devary, Yoram, Caridad Rosette, Joseph A. DiDonato, and Michael Karin. "NF-kappa B activation by ultraviolet light not dependent on a nuclear signal." Science 261, no. 5127 (1993): $1442-1445$.

[69] Schulze-Osthoff, Klaus, Marek Los, and Patrick A. Baeuerle. "Redox signalling by transcription factors $\mathrm{NF}-\kappa \mathrm{B}$ and $\mathrm{AP}-1$ in
lymphocytes."Biochemical pharmacology 50, no. 6 (1995): 735-741.

[70] Piret, Bernard, Sonia Schoonbroodt, and Jacques Piette. "The ATM protein is required for sustained activation of NF-kB following DNA damage."Oncogene 18, no. 13 (1999): 2261-2272.

[71] Waldman, Todd, Kenneth W. Kinzler, and Bert Vogelstein. "p21 is necessary for the p53mediated G1 arrest in human cancer cells." Cancer research 55, no. 22 (1995): 5187-5190.

[72] Bunz, F., A. Dutriaux, C. Lengauer, T. Waldman, S. Zhou, J. P. Brown, J. M. Sedivy, K. W. Kinzler, and B. Vogelstein. "Requirement for p53 and p21 to sustain G2 arrest after DNA damage." Science 282, no. 5393 (1998): 1497-1501.

[73] Tornaletti, Silvia, Dieter Rozek, and Gerd P. Pfeifer. "The distribution of UV photoproducts along the human p53 gene and its relation to mutations in skin cancer." Oncogene 8, no. 8 (1993): 2051-2057.

[74] Tanaka, Hiroshi, Hirofumi Arakawa, Tatsuya Yamaguchi, Kenji Shiraishi, Seisuke Fukuda, Kuniko Matsui, Yoshiki Takei, and Yusuke Nakamura. "A ribonucleotide reductase gene involved in a p53-dependent cell-cycle checkpoint for DNA damage." Nature 404, no. 6773 (2000): 42-49.

[75] Adimoolam, Shanthi, and James M. Ford. "p53 and regulation of DNA damage recognition during nucleotide excision repair." DNA repair 2, no. 9 (2003): 947-954.

[76] Tarasov, Valery, Peter Jung, Berlinda Verdoodt, Dmitri Lodygin, Alexey Epanchintsev, Antje Menssen, Gunter Meister, and Heiko Hermeking. "Differential regulation of microRNAs by p53 revealed by massively parallel sequencing: miR-34a is a p53 target that induces apoptosis and G1-arrest."Cell cycle 6, no. 13 (2007): 1586-1593.

[77] Cayrol, Corinne, Martine Knibiehler, and Bernard Ducommun. "p21 binding to PCNA causes G1 and G2 cell cycle arrest in p53deficient cells." Oncogene16, no. 3 (1998): 311-320.

[78] Toyoshima, Hideo, and Tony Hunter. "p27, a novel inhibitor of G1 cyclin-Cdk protein 
kinase activity, is related to p21." cell 78, no. 1 (1994): 67-74.

[79] El-Deiry, Wafik S., Takashi Tokino, Todd Waldman, Jon D. Oliner, Victor E. Velculescu, Marilee Burrell, David E. Hill et al. "Topological control of p21WAF1/CIP1 expression in normal and neoplastic tissues." Cancer Research 55, no. 13 (1995): 2910-2919.

[80] Wang, J. A. "Ultraviolet radiation downregulates expression of the cell-cycle inhibitor p21WAF1/CIP1 in human cancer cells independently of p53."International journal of radiation biology 75, no. 3 (1999): 301-316. 